\title{
Increased familial risk and evidence of genetic factor in migraine
}

\author{
Michael Bjørn Russell, Jes Olesen
}

\begin{abstract}
Objective-To investigate familial occurrence of migraine with and without aura.

Design-Familial occurrence of migraine with and without aura among first degree relatives and spouses of probands with migraine with or without aura and those who had never had migraine. All interviews of first degree relatives and spouses were done blindly by a neurological resident. The operational diagnostic criteria of the International Headache Society were used.
\end{abstract}

Setting-General population from Copenhagen County.

Subjects-The 378 probands had 1109 first degree relatives and 229 spouses.

Main outcome measures-Patterns of familial aggregation of migraine with and without aura as assessed by calculation of the population relative risk.

Results-Compared with the general population the first degree relatives of probands with migraine without aura had 1.9 times the risk of migraine without aura and 1.4 times the risk of migraine with aura. The first degree relatives of probands with migraine with aura had nearly four times the risk of migraine with aura and no increased risk of migraine without aura. The first degree relatives of probands who had never had migraine had no increased risk of migraine either with or without aura. Spouses of probands with migraine without aura had 1.4 times the risk of migraine without aura whereas spouses of probands with migraine with aura had no increased risk of migraine with aura.

Conclusion-The different familial patterns indicate that migraine without aura and migraine with aura have a different aetiology. Migraine without aura seems to be caused by a combination of genetic and environmental factors whereas migraine with aura is probably determined largely or exclusively by genetic factors.

\section{Introduction}

A gene for familial hemiplegic migraine, a rare autosomal dominant inherited subtype of migraine, was recently mapped to chromosome $19 .^{1}$ This has spurred interest in the possible genetic background of the common types of migraine-migraine without aura (previously known as common migraine) and migraine with aura (previously known as classic migraine). Unfortunately it is much less clear if these types of migraine are inherited. Previous family studies have suggested a genetic factor based on a frequent family history of migraine. ${ }^{2-13}$ The $16-21 \%$ prevalence of migraine in the general population, however, may cause this simply by chance. ${ }^{14} 15$ The family studies also have several shortcomings. Most important are the lack of direct interview of relatives, ${ }^{2-13}$ selection of clinic populations, ${ }^{2-13}$ and lack of distinction between types of migraine..$^{2-1012}$ More valid is the geneticepidemiological approach used in two previous studies. ${ }^{1617}$ The first study found that first degree relatives of probands with migraine had a nonsignificant increased risk of migraine compared with first degree relatives of probands with no migraine. ${ }^{16}$ In the second study first degree relatives of probands with migraine without aura had three times the risk of migraine without aura, and first degree relatives of probands with migraine with aura had twice the risk of migraine with aura compared with the general population. ${ }^{17}$ The genetic epidemiological studies, however, also suffer from lack of direct interview of relatives. Therefore it remains uncertain whether there is a significant familial occurrence of migraine with and without aura and if so whether this is due to genetic or environmental factors.

We determined the prevalence and relative risk of migraine with and without aura in first degree relatives of probands with migraine without aura, with migraine with aura, and who had never had migraine. The risk of migraine with and without aura in spouses was used to elucidate the relative role of genetic and environmental factors, as probands and spouses in part share their environment but differ in genetic constitution.

\section{Subjects and methods} DATA COLLECTION

A sample of 3000 men and 1000 women aged 40 years was drawn from the Danish Central Person Registry. ${ }^{15}$ The probands were found among this study population. All people with migraine with aura were included as probands. An equivalent number of probands with migraine without aura was randomly selected. Similarly, probands who had never had migraine were selected as a random sample of people without self reported migraine. ${ }^{15}$ All those with cooccurrence of the two types of migraine were included as probands. The probands supplied information about their spouse and first degree relatives age 18 years or above. Spouses of probands who had never had migraine were included only if the proband and spouse had a child or children age 18 or above. The spouses and first degree relatives were interviewed by telephone. Their relation to the probands was blinded for the interviewer (MBR). The operational diagnostic criteria of the International Headache Society were used..$^{18}$

Some probands did not allow interview of their family: $3 \%(4 / 132)$ of probands with migraine without aura, $6 \%(8 / 137)$ of probands with migraine with aura, $11 \%(2 / 19)$ of probands with co-occurrence of migraine with and without aura, and $11 \%(13 / 122)$ of probands who had never had migraine. No significant differences regarding migraine reported by the probands were found between families interviewed and those not interviewed. Five probands (four adoptees and one without living relatives) were not included. Only spouses and first degree relatives interviewed were included in the analyses. The participation rate was high among those it was possible to contact; $94 \%$ $(229 / 244)$ of spouses and $93 \%(1109 / 1190)$ of first degree relatives were interviewed.

A total of 48 spouses were not interviewed; reasons were death (three), alcoholism (one), unknown address (17), contact was impossible to obtain (11), there was no telephone and no reply to a standard letter asking for calling back (two), contact of the spouse not allowed by the proband (12), and the spouse declined to participate (two). A total of 460 first degree relatives 
were not interviewed. The primary reason was death (252). Other reasons were dementia (11), mental retardation (four), insanity (three), alcoholism (one), unknown parent (16), unknown address (56), contact impossible to obtain (41), no telephone and no reply to a standard letter asking for calling back (27), contact with certain first degree relatives not allowed by the proband (36), and the first degree relative declined to participate (13). No significant differences were found between the first degree relatives interviewed and those not interviewed regarding migraine reported by probands. Significantly more male than female first degree relatives were not interviewed (161/691 v 91/670; $\mathrm{P}<0.001)$. The project was approved by the Danish ethics committees.

\section{STATISTICAL METHODS}

The prevalences of migraine with and without aura among first degree relatives were estimated by dividing the number of relatives with either condition by the number of first degree relatives.

TABLE —Sex and age specific prevalence of migraine with and without aura per 1000 inhabitants ${ }^{s}$

\begin{tabular}{lccccc}
\hline & \multicolumn{2}{c}{ Migraine with aura } & & \multicolumn{2}{c}{ Migraine without aura } \\
\cline { 2 - 3 } \cline { 5 - 6 } Age (years) & Males & Females & & Males & Females \\
\hline $0-9$ & 9 & 16 & & 27 & 18 \\
$10-19$ & 39 & 47 & & 60 & 110 \\
$20-29$ & 51 & 63 & & 85 & 177 \\
$30-39$ & 63 & 96 & & 93 & 201 \\
$\geqslant 40^{\star}$ & 69 & 106 & & 102 & 221 \\
Overall prevalence & 55 & 82 & & 83 & 177 \\
\hline
\end{tabular}

*Prevalence estimated to be $10 \%$ higher than in the age group $30-39 . .^{22}$

TABLE II-Family history of migraine with and without aura in the different groups of probands. Values in parentheses are numbers of men and women

\begin{tabular}{|c|c|c|c|c|}
\hline \multirow[b]{2}{*}{ Disease in proband } & \multirow[b]{2}{*}{$\begin{array}{c}\text { No of } \\
\text { probands }\end{array}$} & \multirow[b]{2}{*}{$\begin{array}{l}\text { No of first } \\
\text { degree relatives }\end{array}$} & \multicolumn{2}{|c|}{ No of affected first degree relatives } \\
\hline & & & $\begin{array}{l}\text { Migraine } \\
\text { with aura }\end{array}$ & $\begin{array}{c}\text { Migraine } \\
\text { without aura }\end{array}$ \\
\hline Migraine without aura & $126(73 \mathrm{~m}, 53 \mathrm{f})$ & 354 & 42 & 102 \\
\hline Migraine with aura & $127(76 \mathrm{~m}, 51 \mathrm{f})$ & 359 & 111 & 56 \\
\hline Both types of migraine & $17(9 \mathrm{~m}, 8 \mathrm{f})$ & 59 & 11 & 16 \\
\hline Never had migraine & $108(60 \mathrm{~m}, 48 \mathrm{f})$ & 337 & 18 & 58 \\
\hline
\end{tabular}

TABLE III-Prevalence (95\% confidence interval) of migraine with and without aura per 1000 first degree relatives ${ }^{4}$

\begin{tabular}{lcc}
\hline & \multicolumn{2}{c}{ Prevalence among first degree relatives } \\
\cline { 2 - 3 } Disease in proband & Migraine with aura & Migraine without aura \\
\hline Migraine without aura & $118(84$ to 151$)$ & $285(239$ to 331$)$ \\
Migraine with aura & $308(260$ to 356$)$ & $155(118$ to 192$)$ \\
Both types of migraine & $176(80$ to 273$)$ & $246(141$ to 350$)$ \\
Never had migraine & $52(29$ to 75$)$ & $168(130$ to 207$)$ \\
\hline
\end{tabular}

^Prevalences for general population are shown in table $\mathrm{I}$.

TABLE IV-Sex and age standardised risk of migraine with and without aura among first degree relatives and spouses in different groups of probands

\begin{tabular}{|c|c|c|c|c|}
\hline \multirow[b]{2}{*}{ Disease in proband } & \multirow{2}{*}{$\begin{array}{l}\text { Disease in first degree } \\
\text { relative/spouse }\end{array}$} & \multicolumn{2}{|c|}{ No affected } & \multirow{2}{*}{$\begin{array}{l}\text { Population relative } \\
\text { risk }^{\star} \text { (estimated } 95 \% \\
\text { confidence interval) }^{\text {a }}\end{array}$} \\
\hline & & Observed & Expected & \\
\hline \multicolumn{5}{|c|}{ Relatives } \\
\hline \multirow[t]{2}{*}{ Migraine without aura } & Migraine without aura & 102 & 54.84 & $1.86(1.56$ to 2.16$)$ \\
\hline & Migraine with aura & 42 & $29 \cdot 17$ & $1.44(1.03$ to 1.85$)$ \\
\hline \multirow[t]{2}{*}{ Migraine with aura } & Migraine without aura & 56 & $55 \cdot 10$ & $1.02(0.77$ to 1.26$)$ \\
\hline & Migraine with aura & 111 & $29 \cdot 26$ & $3.79(3.21$ to 4.38$)$ \\
\hline \multirow{4}{*}{$\begin{array}{l}\text { Co-occurrence of migraine } \\
\text { with and without aura } \\
\text { Never had migraine }\end{array}$} & Migraine without aura & 16 & $9 \cdot 77$ & $1.64(0.94$ to 2.33$)$ \\
\hline & Migraine with aura & 11 & $5 \cdot 07$ & $2.17(0.98$ to 3.36$)$ \\
\hline & Migraine without aura & 58 & $52 \cdot 41$ & $1.11(0.83$ to 1.39$)$ \\
\hline & Migraine with aura & 18 & $27 \cdot 73$ & $0.65(0.36$ to 0.94$)$ \\
\hline \multicolumn{5}{|c|}{ Spouses } \\
\hline \multirow[t]{2}{*}{ Migraine without aura } & Migraine without aura & 26 & $16 \cdot 85$ & $1.54(1.03$ to 2.06$)$ \\
\hline & Migraine with aura & 6 & $9 \cdot 24$ & $0.65(0.14$ to 1.15$)$ \\
\hline \multirow[t]{2}{*}{ Migraine with aura } & Migraine without aura & 22 & $15 \cdot 45$ & $1.42(0.89$ to 1.96$)$ \\
\hline & Migraine with aura & 6 & $8 \cdot 01$ & $0.75(0.30$ to 1.20$)$ \\
\hline
\end{tabular}

*Observed number of affected relatives divided by expected number.
The risk of familial occurrence was assessed by estimating the population relative risk of the condition in specified groups of relatives. ${ }^{19}$ The risk was calculated according to the following equation:

Probability (relative is affected|proband is affected)

Probability (random member of the population is affected)

A family aggregation is implied when this risk ratio significantly exceeds 1 .

As the prevalence of the conditions depends on sex and age (table I) the value of the denominator was adjusted according to the distribution of sex and age in the group of relatives studied.$^{15}$ Hence, this standardised population relative risk was estimated by dividing the observed number of affected first degree relatives by the expected number according to the prevalence rates in the population. The expected number was calculated by adding the products of the current sex and age specific rates and the number of relatives within each corresponding sex-age category. The adjusted population relative risk of the two types of migraine were estimated separately. The $\chi^{2}$ test was used. A $5 \%$ level of significance was used. The $95 \%$ confidence intervals of the prevalence ratios and the population relative risk were estimated according to the assumption that the numbers affected followed a binomial distribution.

\section{Results}

Adequate information was obtained from 378 of the 410 probands. Table II shows the family history.

Table III shows the prevalences of migraine with and without aura among the first degree relatives. As the prevalence of the conditions depends on sex and age (table I) a sex and age standardised population relative risk was estimated for first degree relatives (table IV). The population relative risk of migraine without aura was 1.9 in first degree relatives of probands with migraine without aura. The risk of migraine with aura in first degree relatives of probands with migraine with aura was $3 \cdot 8$. The risks of migraine with and without aura were $2 \cdot 2$ and $1 \cdot 6$, respectively, in first degree relatives of probands with both types of migraine, whereas first degree relatives of probands who had never had migraine had no increased risk of either type.

Tables V and VI show the effect of selected variables on the population relative risk of migraine with and without aura among first degree relatives of probands with and without aura. The population relative risk was not influenced by generation, sex of the probands, age of probands at onset, or by the age of the first degree relatives. The population relative risk tended to increase, however, with descending generation of probands with migraine without aura.

The 106 spouses of probands with migraine without aura had a significantly increased risk of migraine without aura (table IV). The mean (SD) age at onset of migraine without aura was not significantly different among probands $(17(8.0)$ years) and their spouses $(18.6(10.4))$. The 92 spouses of probands with migraine with aura had no increase in the risk of migraine with aura (table IV). There were 15 spouses of probands with both types of migraine; four had migraine without aura. There were 16 spouses of probands who had never had migraine; one had migraine without aura.

\section{Discussion}

Our study was based on a relatively large group of thoroughly characterised probands from the general population. An epidemiological study conducted in the same area has yielded reliable prevalence rates for the 
general population..$^{1420}$ Thus it was possible to calculate the sex and age standardised population relative risk among the first degree relatives and spouses of our probands. All interviews were done by one interviewer as multiple interviewers invariably increase diagnostic variability. ${ }^{21}$ Diagnosis of migraine is difficult, and only interviews by physicians with experience in diagnosis of headache can be considered as valid in genetic epidemiological studies of migraine. ${ }^{14} 1522$ Migraine is a subjective complaint, which was the reason interviews of spouses and first degree relatives were blinded to avoid interviewer bias. The present study met the highest possible standards for a genetic epidemiological study of migraine in several other ways. A more detailed discussion of the epidemiological data has been published elsewhere. ${ }^{15}$ Migraine without aura and migraine with aura were analysed separately because of clinical and pathophysiological differences. ${ }^{15202324}$ Finally, the quite different familial patterns indicate that the two types of migraine have different causes.

The results concerning migraine without aura were slightly surprising. The risk of migraine without aura among first degree relatives of probands with migraine

TABLE V-Effect of selected variables on population relative risk of migraine without aura among first degree relatives of probands with migraine without aura

\begin{tabular}{|c|c|c|c|c|}
\hline \multirow[b]{2}{*}{ Variable } & \multirow{2}{*}{$\begin{array}{l}\text { Total No of first } \\
\text { degree relatives }\end{array}$} & \multicolumn{2}{|c|}{$\begin{array}{c}\text { No of affected } \\
\text { first degree relatives }\end{array}$} & \multirow{2}{*}{$\begin{array}{l}\text { Population relative } \\
\text { risk }^{\star} \text { (estimated } 95 \% \\
\text { confidence interval) }\end{array}$} \\
\hline & & Observed & Expected & \\
\hline \multicolumn{5}{|l|}{ Generation: } \\
\hline Parents & 151 & 40 & $25 \cdot 52$ & $1.56(1.16$ to 1.97$)$ \\
\hline Siblings & 167 & 51 & $26 \cdot 12$ & $1.95(1.51$ to 2.40$)$ \\
\hline Children & 36 & 11 & $3 \cdot 21$ & $3.43(1.65$ to 5.21$)$ \\
\hline \multicolumn{5}{|c|}{ Sex of proband/relative: } \\
\hline Male/male & 110 & 15 & $10 \cdot 40$ & $1.44(0.76$ to 2.12$)$ \\
\hline Male/female & 102 & 38 & $21 \cdot 48$ & $1.77(1.32$ to 2.21$)$ \\
\hline Female/male & 61 & 18 & $5 \cdot 83$ & $3.09(1.89$ to 4.29$)$ \\
\hline Female/female & 81 & 31 & $17 \cdot 11$ & $1.81(1.31$ to 2.31$)$ \\
\hline \multicolumn{5}{|c|}{ Age (years) of probands at onset: } \\
\hline $0-9$ & 60 & 16 & $9 \cdot 08$ & $1.76(1.04$ to 2.48$)$ \\
\hline $10-19$ & 173 & 54 & $26 \cdot 65$ & $2.03(1.63$ to 2.41$)$ \\
\hline $20-29$ & 96 & 24 & 14.96 & $1.60(1.05$ to 2.16$)$ \\
\hline $30-39$ & 25 & 8 & $4 \cdot 15$ & $1.93(0.76$ to 3.09$)$ \\
\hline \multicolumn{5}{|c|}{ Age (years) of relative at survey: } \\
\hline $18-19$ & 24 & 6 & 1.79 & $3.35(0.76$ to 5.94$)$ \\
\hline $20-29$ & 20 & 7 & $2 \cdot 56$ & $2.73(1.26$ to 4.21$)$ \\
\hline $30-39$ & 70 & 17 & $10 \cdot 40$ & $1.63(0.96$ to 2.30$)$ \\
\hline $40-49$ & 70 & 24 & $11 \cdot 66$ & 2.05 (1.39 to 2.73$)$ \\
\hline $50-59$ & 23 & 11 & 3.77 & $2.92(0.00$ to 6.47$)$ \\
\hline $60-69$ & 99 & 27 & $17 \cdot 12$ & 1.58 (1.06 to 2.09$)$ \\
\hline$\geqslant 70$ & 48 & 10 & $7 \cdot 51$ & $1.33(1.03$ to 1.64$)$ \\
\hline
\end{tabular}

*Observed number of affected relatives divided by expected number.

TABLE VI-Effect of selected variables on population relative risk of migraine with aura among first degree relatives of probands with migraine with aura

\begin{tabular}{|c|c|c|c|c|}
\hline \multirow[b]{2}{*}{ Variable } & \multirow{2}{*}{$\begin{array}{l}\text { Total No of first } \\
\text { degree relatives }\end{array}$} & \multicolumn{2}{|c|}{$\begin{array}{c}\text { No of affected } \\
\text { first degree relatives }\end{array}$} & \multirow{2}{*}{$\begin{array}{l}\text { Population relative } \\
\text { risk }^{\star} \text { (estimated } 95 \% \\
\text { confidence interval) }^{\text {ande }}\end{array}$} \\
\hline & & Observed & Expected & \\
\hline $\begin{array}{l}\text { Generation: } \\
\text { Parents } \\
\text { Siblings } \\
\text { Children }\end{array}$ & $\begin{array}{r}143 \\
174 \\
42\end{array}$ & $\begin{array}{r}55 \\
47 \\
9\end{array}$ & $\begin{array}{r}13 \cdot 13 \\
14 \cdot 04 \\
2 \cdot 10\end{array}$ & $\begin{array}{l}4.19(3.60 \text { to } 4.78) \\
3.35(2.53 \text { to } 4.17) \\
4.29(1.54 \text { to } 7.03)\end{array}$ \\
\hline $\begin{array}{c}\text { Sex of proband/re } \\
\text { Male/male } \\
\text { Male/female } \\
\text { Female/male } \\
\text { Female/female }\end{array}$ & $\begin{array}{r}106 \\
107 \\
68 \\
78\end{array}$ & $\begin{array}{l}34 \\
35 \\
13 \\
29\end{array}$ & $\begin{array}{r}7 \cdot 00 \\
10 \cdot 60 \\
4 \cdot 22 \\
7 \cdot 46\end{array}$ & $\begin{array}{l}4.85(3.51 \text { to } 6.20) \\
3.30(2.40 \text { to } 4.20) \\
3.08(1.57 \text { to } 4.58) \\
3.89(2.77 \text { to } 5.01)\end{array}$ \\
\hline $\begin{array}{c}\text { Age (years) of pro } \\
0-9 \\
10-19 \\
20-29 \\
30-39\end{array}$ & $\begin{array}{r}53 \\
153 \\
73 \\
80\end{array}$ & $\begin{array}{l}13 \\
56 \\
18 \\
24\end{array}$ & $\begin{array}{r}4 \cdot 04 \\
12 \cdot 71 \\
6 \cdot 02 \\
6 \cdot 47\end{array}$ & $\begin{array}{l}3.22(1.70 \text { to } 4.73) \\
4.41(3.49 \text { to } 5.33) \\
2.99(1.78 \text { to } 4.20) \\
3.71(2.48 \text { to } 4.93)\end{array}$ \\
\hline $\begin{array}{l}\text { Age (years) of rela } \\
18-19 \\
20-29 \\
30-39 \\
40-49 \\
50-59 \\
60-69 \\
\geqslant 70\end{array}$ & $\begin{array}{l}24 \\
26 \\
67 \\
78 \\
21 \\
93 \\
50\end{array}$ & $\begin{array}{r}5 \\
7 \\
14 \\
25 \\
5 \\
39 \\
16\end{array}$ & $\begin{array}{l}1 \cdot 06 \\
1.48 \\
5 \cdot 21 \\
6 \cdot 68 \\
1 \cdot 71 \\
8 \cdot 68 \\
4 \cdot 45\end{array}$ & $\begin{array}{l}4.72(1.02 \text { to } 8.41) \\
4.73(1.77 \text { to } 7.69) \\
2.68(1.45 \text { to } 3.93) \\
3.74(2.54 \text { to } 4.94) \\
2.92(0.60 \text { to } 5.25) \\
4.61(3.36 \text { to } 5.63) \\
3.60(2.14 \text { to } 5.05)\end{array}$ \\
\hline
\end{tabular}

*Observed number of affected relatives divided by expected number.

\section{Key messages}

- Familial aggregation of migraine has previously been uncertain

- Migraine exists in two major forms: migraine with and without aura

- First degree relatives have increased risk of the same subtype of migraine as the proband, spouses show an increased risk only for migraine without aura

- The different familial patterns indicate that the two types of migraine have a different aetiology

- Future research should be directed towards analyses of the mode of inheritance and genetic linkage studies

without aura was increased only by a factor of two compared with the risk in the general population (population relative risk) or compared with the risk among first degree relatives of probands who had never had migraine. The risk of migraine without aura among spouses was increased by a factor of 1.5 . This cannot be explained by assortative mating as migraineurs do not have specific personalities, marital status, education, or employment. ${ }^{25}$ Nor can it be explained by environmental factors alone as age at onset of migraine without aura was almost the same in probands and spouses. Presumably a combination of shared environment and simple chance may explain the effect we observed. The increased risk of migraine without aura among spouses may explain the trend toward an increased population relative risk among children of probands with migraine without aura (table V). The results indicate that both genetic and environmental factors may have a relatively weak influence on migraine without aura.

The pattern in migraine with aura was quite different. The risk among first degree relatives of probands with migraine with aura was increased by a factor of 3.8 as compared with the general population or by a factor of six as compared with the risk among first degree relatives of probands who had never had migraine. Spouses of probands with migraine with aura had no increased risk of migraine with aura. The results suggest that genetic factors are of considerable importance. In this context it should be pointed out that because of the high prevalence of migraine with aura $(7 \%)$ the maximum increase in the population relative risk (when all first degree relatives are affected) is 15 .

In summary our results indicate that migraine with and without aura have a different aetiology. The moderate but significantly increased risk of migraine without aura among first degree relatives of probands with migraine without aura is most likely due to a combination of both genetic and environmental factors, whereas the much more increased risk of migraine with aura among first degree relatives of probands with migraine with aura seems to depend primarily or exclusively on genetic factors.

We are indebted to Professor Thorkild I A Sørensen, Institute of Preventive Medicine, Copenhagen Health Services, for helpful suggestions in planning the project and comments on the paper.

Funding: University of Copenhagen, Foundation for Migraine Research, Foundation for Experimental Research in Neurology, Danish Migraine Society, Danish Medical Association Research Fund, Cool Sorption Foundation, and Foundation for Medical Research in Greater Copenhagen, the Faroe Islands, and Greenland.

Conflict of interest: None. 
1 Joutel A, Bousser MG, Biousse V, Labauge P, Chabriat H, Nibbio A, et al. A gene for familial hemiplegic migraine maps to chromosome 19. Nat Gene 1993;5:40-5.

2 Christiansen V. Rapport sur la migraine (étude clinique). Rev Neurol (Paris) 1925;32:854-81.

3 Allen W. The inheritance of migraine. Arch Intern Med 1930;13:590-9.

4 Goodell H, Lewontin R, Wolff HG. Familial occurrence of migraine headache. A study of heredity. Archives of Neurology and Psychiatry 1954;72:325-34.

5 Selby G, Lance JW. Observations on $\mathbf{5 0 0}$ cases of migraine and allied vascular headache. I Neurol Neurosurg Psychiatry 1960;23:23-36.

6 Dalsgaard-Nielsen T. Migraine and heredity. Acta Neurol Scand 1965;41: 287-300.

7 Barolin GS, Sperlich D. Migränefamilien. Beitrag zum genetischen Aspekt des Migrăneleidens. Fortschr Neurol Psychiatr 1969;37:521-44.

8 Dalsgaard-Nielsen T, Ulrich J. Prevalence and heredity of migraine and migrainoid headaches among 461 Danish doctors. Headache 1973;12 168-72.

9 Baier WK. Genetics of migraine and migraine accompagnée: A study of eightyone children and their families. Neuropediatrics 1985;16:84-91.

10 Devoto M, Lozito A, Staffa G, D'Alessandro R, Sacquegna T, Romeo G. Segration analys of migraine in 128 families. Cephalalsia 1986:6:101-5.

11 D'Amico D, Leone M, Macciardi F, Valentini S, Bussone G. Genetic transmission of migraine without aura: a study of 68 families. Ital $₹$ Neurol transmission of mi

12 Vilatela MEA, Pedroza FG, Ziegler DK, Mendez AG. Familial migraine in a Mexican population. Neuroepidemiology 1992;11:46-9.

13 Mochi M, Sangiorgi S, Cortelli P, Carelli V, Scapoli C, Crisci M, et al. Testing models for genetic determination in migraine. Cephalalgia 1993;13:389-94.

14 Rasmussen BK, Jensen R, Scroll M, Olesen J. Epidemiology of headache in general population—a prevalence study. I Clin Epidemiol 1991;44:1 147-57.

15 Russell MB, Rasmussen BK, Thorvaldsen P, Olesen J. Prevalences and sex- ratios of the subtypes of migraine. A population based epidemiological survey of four thousand 40 year old males and females. Int $\mathcal{f}$ Epidemio 1995;24:612-8.

16 Waters WE. Migraine: intelligence, social class and familial prevalence. $B M \mathcal{f}$ 1971 ;i:77-81.

17 Russell MB, Hilden J, Serensen SA, Olesen J. Familial occurrence of migraine without aura and migraine with aura. Neurology 1993;43:1369-73.

18 Headache Classification Committee of the International Headache Society. Classification and diagnostic criteria for headache disorders, cranial Classification and diagnostic critia for headache

19 Weiss KM, Chakraborty R, Majumder PP, Smouse PE. Problems in the assessment of relative risk of affected individuals. Foumal of Chronic Disease 1982;35:539-51.

20 Rasmussen BK, Olesen J. Migraine with aura and migraine without aura: an epidemiological study. Cephalalgia 1992;12:221-8.

21 Leone M, Filippini G, D'Amico D, Farinotti M, Bussone G. Assessment of International Headache Society diagnostic criteria: a reliability study. Cephalalgia 1994;14:280-4.

22 Henry P, Michel P, Brochet B, Dartiques JF, Tison S, Salamon R, GRIM. A nationwide survey of migraine in France: prevalence and clinical features in adults. Cephalalgia 1992:12:229-37.

23 Olesen J, Larsen B, Lauritzen M. Focal hyperemia followed by spreading oligemia and impaired activation of rCBF in classic migraine. Ann Neurol 1981;9:344-52.

24 Olesen J. Tfelt-Hansen P, Henriksen L, Larsen B. The common migraine attack may not be initiated by cerebral ischaemia. Lancet 1981;ii:438-40.

25 Rasmussen BK. Migraine and tension type headache in a general population: psychosocial factors. Int $\mathcal{f}$ Epidemiol 1992;21:1138-43.

(Accepted 15 fune 1995)

\section{Exercise responses and psychiatric disorder in chronic fatigue syndrome}

\section{Russell J M Lane, Adrian P Burgess, Janis Flint, Massimo Riccio, Leonard C Archard}

\section{Academic Unit of Neuroscience, Charing Cross and Westminster Medical School, London W6 8RF \\ Russell J M Lane, consultant} neurologist

Department of Psychiatry, Charing Cross and Westminster Medical School, London W6 8RF Adrian P Burgess, lecturer in psychology

Janis Flint, senior clinical psychologist

Massimo Riccio, consultant psychiatrist

\section{Department of}

Biochemistry, Charing

Cross and Westminster

Medical School, London W6 8RF

Leonard C Archard, reader in molecular pathology

Correspondence to:

Dr Lane.

BMF 1995;311:544-5
Fatigue, exercise intolerance, and myalgia are cardinal symptoms of the chronic fatigue syndrome, but whether they reflect neuromuscular dysfunction or are a manifestation of depression or other psychiatric or psychological disorders diagnosed in a high proportion of fatigued patients in the community is unclear. ${ }^{1}$ In previous studies patients with the chronic fatigue syndrome showed exercise intolerance in incremental exercise tests, which seemed to be related to an increased perception of effort; also, blood lactate concentrations in some patients tended to increase more rapidly than normal at low work rates, implying inefficient aerobic muscle metabolism. ${ }^{2}$ We examined venous blood lactate responses to exercise at a work rate below the anaerobic threshold in relation to psychiatric disorder.

\section{Patients, methods, and results}

We studied 96 consecutive patients meeting the Oxford criteria for diagnosis of the chronic fatigue syndrome ${ }^{3}$ by using the subanaerobic threshold exercise test. ${ }^{4}$ Subjects pedalled an electronically braked bicycle ergometer for 15 minutes at $90 \%$ of the predicted work rate at their anaerobic threshold, based on age, weight, and sex; venous blood lactate concentrations were measured before, immediately after, and 30 minutes after exercise. Continuous electrocardiographic monitoring allowed measurement of mean heart rate during exercise. An abnormal result was defined as lactate concentrations exceeding the upper $99 \%$ reference limit for normal control subjects at two or more time points. We screened a convenience sample of 43 of the 96 patients using 11 established neuropsychological and psychiatric instruments, including the present state examination, for assessment of psychiatric caseness and prediction of psychiatric diagnoses. ${ }^{5}$

The study group comprised 41 men and 55 women of similar age range. Duration of symptoms ranged from six months to 20 years (mean 43.5 (SD 11.6) months). All patients were ambulant.

Thirty one (12 men, 19 women) of the 96 patients $(32 \%)$ had abnormal lactate responses to exercise (subanaerobic threshold exercise test positive). These patients did not differ significantly from those with normal lactate responses in age, sex, or duration of symptoms. Twenty nine patients $(30 \%)$ had mean heart rates above the predicted upper $95 \%$ reference limit for normal controls. ${ }^{4}$ However, there was no significant difference between the proportions with abnormal heart rates among those with abnormal or normal lactate responses (7/31 v 22/63 (no data in two cases); odds ratio $0.54(95 \%$ confidence interval 0.2 to 1.46$)$ ).

The 43 patients studied by psychological and psychiatric tests did not differ significantly from the 53 other patients in terms of age (mean $34.6 v 34.4$ years); mean duration of symptoms (43.6 $v 37 \cdot 1$ months); sex distribution (19 men $v 24$ men); whether they were working (27 unemployed $v 27$ unemployed (not recorded in two cases)); or proportion with abnormal lactate responses $(15 / 43 v 16 / 53)$. Eighteen of the 43 $(42 \%)$ patients fulfilled criteria for psychiatric caseness. Diagnoses were neurotic depression (12 patients), manic depression (3), phobic anxiety (2), and anxiety state (1). Patients with normal lactate responses were more likely to fulfil criteria for psychiatric caseness than those with abnormal lactate responses (15/28 v $3 / 15$; odds ratio $4.6(1.06$ to $20 \cdot 1))$.

\section{Comment}

Patients with symptoms that precluded or severely restricted physical activity might be expected to show increased lactate responses to exercise as a result of "deconditioning." However, abnormal lactate responses were seen in only a third of our cases, and we found no relation between lactate responses and duration of symptoms or any other demographic variable. Furthermore, although $30 \%$ of all patients had abnormally high heart rates during exercise, a high heart rate was as common in patients with normal lactate responses as it was in those with abnormal responses. Patients with the chronic fatigue syndrome who also had psychiatric disorders such as depression, which is commonly associated with fatigue and inactivity, might also be expected to be unfit and to have abnormal exercise results; but the converse proved to be true.

Our results suggest that some patients with the chronic fatigue syndrome have impaired muscle 